\title{
Stabilization of DC Micro-Grid Systems by Using the Loop-Cancellation Technique
}

\author{
Jakkrit Pakdeeto, Kongpan Areerak, Member, IEEE, Serhiy Bozhko, Senior Member, IEEE, \\ and Kongpol Areerak
}

\begin{abstract}
DC micro-grid systems feed power to constant power loads via transmission lines. Although these systems are commonly used worldwide, constant power loads have negative impedance effects. These loads can significantly degrade the system stability. Therefore, stability study is very important to avoid inefficient operations. The model proposed in this paper can be derived by using a combination of the DQ method and the generalized state-space averaging method. This model is suitable for analyzing the system stability using the eigenvalue theorem. For stability analysis, the proposed DC micro-grid system will be unstable before reaching the rated power when the irradiance is equal to $0 \mathrm{~W} / \mathrm{m}^{2}$. Consequently, the loop-cancellation technique is applied to mitigate the unstable operation until the operation at the rated power can be achieved. Experimental and simulation results were used to confirm the theoretical analysis. The system performed well, and the results proved that the system could be stabilized by using the proposed technique.
\end{abstract}

Index Terms--DC micro-grid system, Mitigation technique, Stability analysis, Mathematical model, Loop-cancellation.

\section{INTRODUCTION}

$\mathrm{T}_{\mathrm{s}}^{\mathrm{o}}$ achieve a sustainable future, significant efforts worldwide have been directed toward the exploitation of renewable energy sources [1], such as wind, tidal, photovoltaic $(\mathrm{PV})$, and geothermal energy. These are considered as "clean energy" because they do not release any greenhouse gases. Typically, renewable sources provide their outputs in the form of DC electric power [2,3], and they are integrated into the existing grids using DC micro-grid systems (DCMGs). Within these micro-grids (MGs), the renewable sources are interfaced using power electronics that offers great capabilities and flexibility in managing the power flow. Therefore, DCMGs can be used in many applications [4-6]. The advantage of DCMGs is their flexibility in power management because each MG can be independently controlled and can supply electrical power to the loads [7]. The literature reviews in $[8,9]$ show that one of the DCMG loads is the controlled

This work was supported by Suranaree University of Technology. (Corresponding author: Kongpan Areerak.)

J. Pakdeeto is with the Department of Teacher Training in Electrical Engineering, Faculty of Technical Education, King's Mongkut University of Technology (KMUTNB), Bangkok 10800, Thailand. (e-mail: jakkritpa@kmutnb.ac.th).

K-N. Areerak, and K-L. Areerak are with the School of Electrical Engineering, Suranaree University of Technology, Nakhon Ratchasima 30000, Thailand. (e-mail: kongpan@ @ut.ac.th; kongpol@sut.ac.th).

S. Bozhko is with the Department of Electrical and Electronic Engineering, University of Nottingham, Nottingham NG7 2RD, U.K (e-mail: serhiy.bozhko@nottingham.ac.uk). power converter because this converter is easy to control and maintain. However, the behaviors of loads that are tightly controlled by power electronics can be similar to those of a constant power load (CPL) [10-12]; such behaviors can degrade the system stability and lead to system disintegration, and collapse, and non-compliance in power quality [11, 12]. With the increase in the share of CPL in the MG, the system may become unstable even at power levels that are lower than those of the MG-rated power. Therefore, a stability analysis is required at early design stages to ensure safe and stable MG operations. This paper investigates the stability conditions for MGs in PV generation stations.

It is well-known that the power converter models in terms of the differential equations derived from the basic circuit theory are normally time-varying because of the switching actions of the switching devices [13]. It is very difficult to use a time-varying model for stability analysis. Therefore, a timeinvariant model was used for the stability problems in this paper. To derive the time-invariant model, averaging approaches, such as the generalized state-space averaging (GSSA) and direct quadrature (DQ) methods, are normally used. From [14-19], the GSSA and DQ methods are suitable to analyze the DC/DC converters and the three-phase power converters, respectively. For the proposed power system, the boost converter is used for tracking the maximum power point (MPP) of the PV array, whereas the three-phase bi-directional voltage source converter (VSC) is used for DCMG power management. Hence, the combination between the GSSA and DQ approaches are presented to derive the time-invariant model of the proposed power system consisting of both DC/DC converters and three-phase power converters. After using the GSSA and DQ methods, the time-invariant model of DCMGs can be achieved, which is suitable for stability analysis using the eigenvalue theorem $[20,21]$. The unstable point can then be predicted. However, the stability analysis can only predict the unstable operation in which it cannot mitigate the unstable operation. If this unstable point occurs within the rated power of the system, instability mitigation techniques are required. From the literature reviews, two approaches were used to eliminate the effect of the CPL: passive and active [22]. For the passive method [23], it is a simple technique to increase the system stability by adding the passive components, e.g., a resistor, a resistor with capacitor, or a resistor with inductor into the system to increase system damping. The passive technique has a lot of drawbacks such as an increase the system size, weight, and price and system power losses resulting in a decreased system performance. 


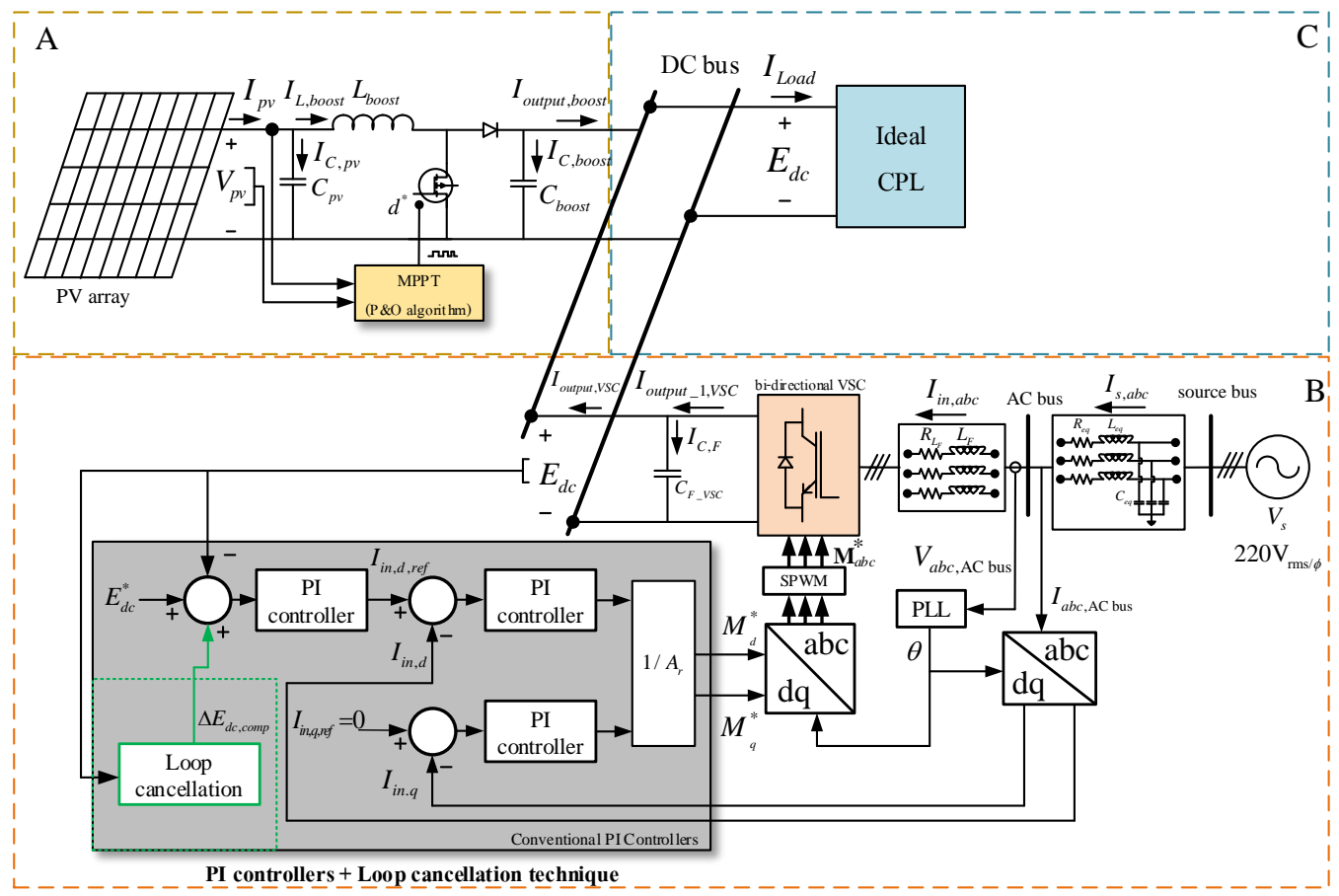

Fig. 1. Proposed DCMGs feeding an ideal CPL.

Therefore, the active method is widely used for the instability mitigation. As for the active method, the control structure is modified without adding the passive components. The virtual damping is created inside the controller loop to stabilize the system [22, 24]. As a result, higher efficiency and reliability can be achieved. Active stabilization can be performed in three ways in which each of them has both benefits and limitations [22]. The first way is the stabilization from the source side [25]. In this way, it can be applied to only the controllable source in which it does not affect to the load performance. The load side stabilization is the second way to mitigate the instability scenario [26]. The load side mitigation can affect to load performance, but it can directly compensate the CPL effect. If the feeder consists of uncontrolled converter and the load performance is very important, the third way should be used. It is located between the feeder and load in which the auxiliary circuits are required [22, 27]. The structure modification by adding an intermediate circuitry will increase cost and losses. Therefore, in this paper, the compensated signal from the source side is selected because it does not affect the load performance [27], and other components are not required in the system [27, 28], resulting in modified only controller structure. Moreover, the considered system of DCMGs has the bi-directional VSC which can be easily modified the code inside the controller. From the literature reviews in [29, 30], the active damping has been used for stabilization in the DCMGs by adding the virtual resistance inside the control loop in which it is the linear feedback active damping method [22]. However, the linearization feedback approach for mitigation can be used to compensate for a limited amount of CPL [28]. Thus, this paper investigates the DCMGs under the nonlinear active mitigation technique known as loop-cancellation [27, 28]. To the best of our knowledge, this technique for the DCMGs has not been reported in any previous publications. It is possible to directly eliminate the CPL effect by injecting the compensated signal into the control loop. The simulation and experimental results confirm that the loop-cancellation technique can compensate for the effect of the CPL such that the system provides stable operations within the rated power range. Experimental results have proved that the loop-cancellation technique is an efficient way for improving the performance of DCMGs.

This paper consists of six sections. Section I presents the introduction to the research. Section II describes the modeling of the system; the stability analysis technique applied to the proposed DCMGs is explained in Section III. System stabilization by using the loop-cancellation technique is addressed in Section IV. The experimental results to confirm the analytical results are presented in Section V, which is followed by the conclusions in Section VI.

\section{MODELING OF THE DCMGS FEEDING AN IDEAL CPL}

The DCMGs being investigated is shown in Fig. 1; the rated power of the proposed DCMGs was set as $100 \mathrm{~kW}$. This system consists of three parts. In the first part (A), the PV array is the renewable energy source in which the MPP can be tracked by using a boost converter [31]. This converter receives power from the PV array and supplies it into the DC bus. In the second part (B), the connection between the DCMG and the main grid AC system via the bi-directional VSC is presented. This VSC is used for DCMG power management, and the DC bus voltage is controlled by VSC using the proportional integral (PI) control with the loopcancellation technique. The last part (C) is an ideal CPL, which represents the tight control of the power electronic circuits, such as the output voltage-controlled converter and the speed controlled of the motor drives.

It is known that the CPL can degrade system stability [11, 32, 33]. Many research articles have described the methods for the unstable point prediction using a mathematical model [34-36]. However, the power converter 
model is usually time-varying because of the switching action. Analyzing the system stability via the linear control theory is complicated for this model. Literature review shows that the DQ and the GSSA methods are suitable for modeling the three-phase systems and DC/DC converters, respectively. Hence, the GSSA and DQ methods were used to derive the time-invariant model. In this paper, the proposed DCMG models can be derived by using a combination of the DQ method and the GSSA approach $[35,37]$. The important assumptions used to derive the mathematical model are that the bi-directional VSC have to be operated under the continuous conductance mode (CCM) and the dynamic response of $\mathrm{P} \& \mathrm{O}$ algorithm is very fast. Applying both GSSA and DQ methods to the system in this study will lead to the establishment of a time-invariant model suitable for stability analysis using the eigenvalue theorem [35, 36]. To obtain the mathematical model of the DCMGs, each part of the proposed system was analyzed. As a result, the dynamic model of the proposed system shown in Fig. 1 without the loop-cancellation technique is given in (A-1). However, the model with loop-cancellation approach will be explained in section IV of this paper. To validate the mathematical model (A-1), the exact topological simulation via MATLAB/SimPowerSystem ${ }^{\circledR}$ is used. For the model validation, the system parameters are defined as follows: $V_{s}=$ $220 \mathrm{~V}_{\mathrm{rms} / \phi}, R_{e q}=0.1 \Omega, L_{e q}=10 \mu \mathrm{H}, C_{e q}=2 \mathrm{nF}, L_{F}=5 \mathrm{mH}$, $R_{L F}=0.1 \Omega, C_{F}=1000 \mu \mathrm{F}, L_{b o o s t}=5 \mathrm{mH}, N_{p}=40, N_{s}=9$, $K_{p v}=0.2445, K_{i v}=38.1977, K_{p i}=-0.0067, K_{i i}=-5.2820$, $E_{d c}=1500 \mathrm{~V}$ and $I_{r r}=1000 \mathrm{~W} / \mathrm{m} 2$, The model validation result while the CPL is changed from $80 \mathrm{~kW}$ to $95 \mathrm{~kW}$ is shown in Fig. 2.

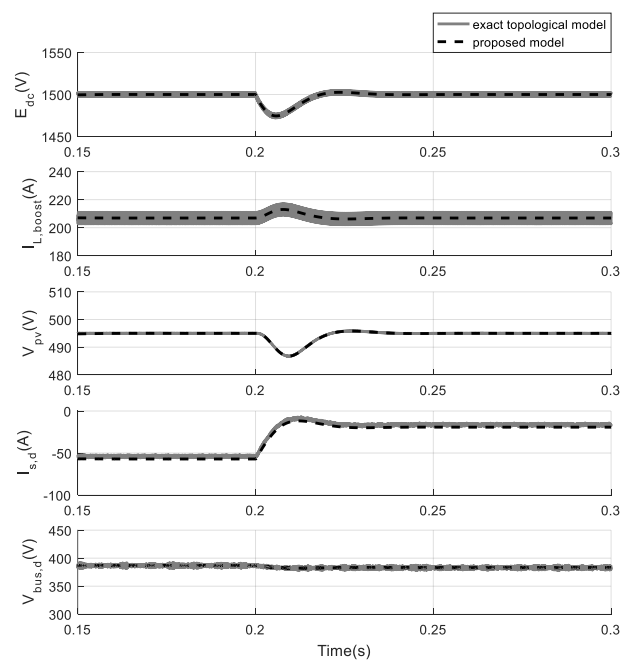

Fig. 2. Mathematical model validation in the case without loop-cancellation technique.

The validation result in Fig. 2 can confirm that the time invariant model derived from the combination between GSSA and DQ methods is correct in which it can be used for the system stability analysis as described in Section III.

\section{Stability ANALYSIS OF DCMGS}

From (A-1), it is clear that the DCMGs without the loopcancellation technique are governed by a nonlinear system of equations. The first-order term of the Taylor series expansion was used to provide the linearized model suitable for system stability analysis in the linear domain. The linearized model of (A-1) is as follows:

$$
\left\{\begin{array}{l}
\dot{x}=\mathbf{A}\left(\mathbf{x}_{\mathbf{o}}, \mathbf{u}_{\mathbf{o}}\right) \delta \mathbf{x}+\mathbf{B}\left(\mathbf{x}_{\mathbf{o}}, \mathbf{u}_{\mathbf{o}}\right) \delta \mathbf{u} \\
\delta \mathbf{y}=\mathbf{C}\left(\mathbf{x}_{\mathbf{o}}, \mathbf{u}_{\mathbf{o}}\right) \delta \mathbf{x}+\mathbf{D}\left(\mathbf{x}_{\mathbf{o}}, \mathbf{u}_{\mathbf{o}}\right) \delta \mathbf{u}
\end{array}\right.
$$

The matrices A, B, C, and D are the Jacobean matrices of the DCMGs in the form of the state-space model. Each element of this matrix depends on the system operation point. The system eigenvalues can be calculated as follows [35]:

$$
\operatorname{det}[\lambda \mathbf{I}-\mathbf{A}]=0
$$

The system is stable if

$$
\text { real } \lambda_{i}<0
$$

where $i=1,2,3, \ldots, n$ ( $n$ is the number of the state variable).

The stability of the proposed DCMGs with the ideal CPL (shown in Fig. 1) was analyzed. The DCMGs properties were investigated under the following operation conditions. For the first condition, the irradiance was set to $1000 \mathrm{~W} / \mathrm{m}^{2}$; the maximum irradiance standard has been reported in [38], and the DC bus voltage was controlled at $1500 \mathrm{~V}$. The remaining parameters are similar as the part of model validation of Fig. 2. The eigenvalues for the first case are shown in Fig. 3(a), where the dominant pole is highlighted in the gray area. The system will become unstable at a CPL equal to $220 \mathrm{~kW}$. The results show that the system is unstable after the rated power. Therefore, the mitigation approach will not be applied to this condition. The time-domain simulation result to confirm the unstable point predicted by eigenvalue analysis is shown in Fig. 3(b). The system becomes unstable when the CPL power reaches $220 \mathrm{~kW}$, as predicted by eigenvalue analysis.

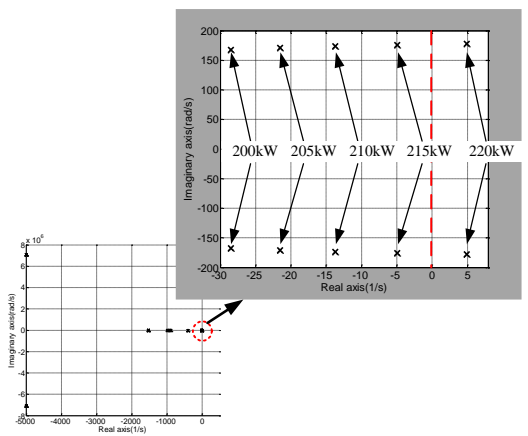

(a) Eigenvalues of the first case.



Fig. 3. Stability analysis of the first case. 
For the second condition, the irradiance was set to 500 $\mathrm{W} / \mathrm{m}^{2}$, and the DC bus voltage was controlled at $1500 \mathrm{~V}$. The dominant poles for this case are shown in Fig. 4(a); clearly, the system will lose stability if the CPL power reached $155 \mathrm{~kW}$. The simulation result to validate the unstable condition of this case is shown in Fig. 4(b). In this case, the unstable point will occur at a CPL equal to $155 \mathrm{~kW}$. This CPL level is much larger than the rated power. Therefore, no mitigation technique is required for this condition.

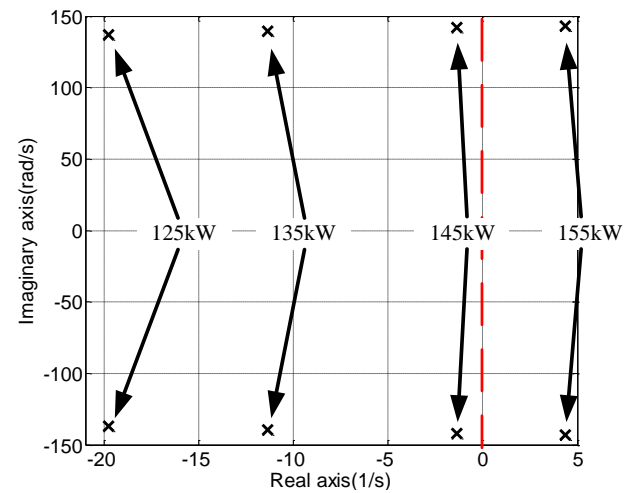

(a) Eigenvalues of the second case.
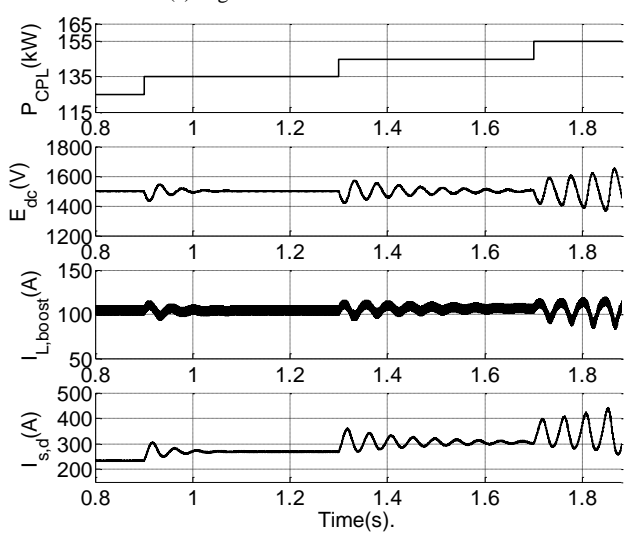

(b) Simulation results of the second case.

Fig. 4. Stability analysis of the second case.

From Fig. 3 to Fig. 4, the irradiance has been shown to significantly affect the stability condition of the DCMGs. To evaluate this effect, the details of the effect of the irradiance will be described as follows:

\section{Effect of irradiance variation}

In the previous results, the irradiance was equal to 500 $\mathrm{W} / \mathrm{m}^{2}$ and $1000 \mathrm{~W} / \mathrm{m}^{2}$; Figs. 3 and 4 show that these cases are stable within the rated power equal to $100 \mathrm{~kW}$. However, the unstable point is not the same when the irradiance is changed. Therefore, the study on the effect of irradiance changing needs to be described. To evaluate this effect, the eigenvalues are plotted in Fig. 5(a) when the irradiance is changed from 0 $\mathrm{W} / \mathrm{m}^{2}$ to $250 \mathrm{~W} / \mathrm{m}^{2}, 500 \mathrm{~W} / \mathrm{m}^{2}, 750 \mathrm{~W} / \mathrm{m}^{2}$, and $1000 \mathrm{~W} / \mathrm{m}^{2}$ with fixed CPL equal to the rated power of $100 \mathrm{~kW}$. Fig. 5(a) clearly shows that the system will be more stable when the irradiance is increased. To validate the result of Fig. 5(a), a simulation was performed in MATLAB/SimPowerSystem ${ }^{\circledR}$ under an irradiance equal to $0 \mathrm{~W} / \mathrm{m}^{2}$. The DC bus voltage was controlled at $1500 \mathrm{~V}$ while the CPL was increased from
$85 \mathrm{~kW}$ to $90 \mathrm{~kW}, 95 \mathrm{~kW}$, and $100 \mathrm{~kW}$ at the time instants $2.1 \mathrm{~s}, 2.5 \mathrm{~s}$, and $2.9 \mathrm{~s}$, respectively.

In Fig. 5(b), it can be seen at $t=2.9 \mathrm{~s}$, the system becomes unstable (when CPL is $100 \mathrm{~kW}$ ). However, the system can recover stability automatically when the irradiance is increased from $0 \mathrm{~W} / \mathrm{m}^{2}$ to $250 \mathrm{~W} / \mathrm{m}^{2}$ at $t=3 \mathrm{~s}$. After $t>3 \mathrm{~s}$, the DC bus voltage was well controlled at $1500 \mathrm{~V}$. This case shows that if the irradiance was more than $0 \mathrm{~W} / \mathrm{m}^{2}$, the system can be operated in the full power range $(0-100 \mathrm{~kW})$ without the requirement to address stability issues. The simulation results in Fig. 5(b) clearly indicate that the irradiance level can affect the system stability, and the system will become more stable without the modification of any strategies into the DCMGs.

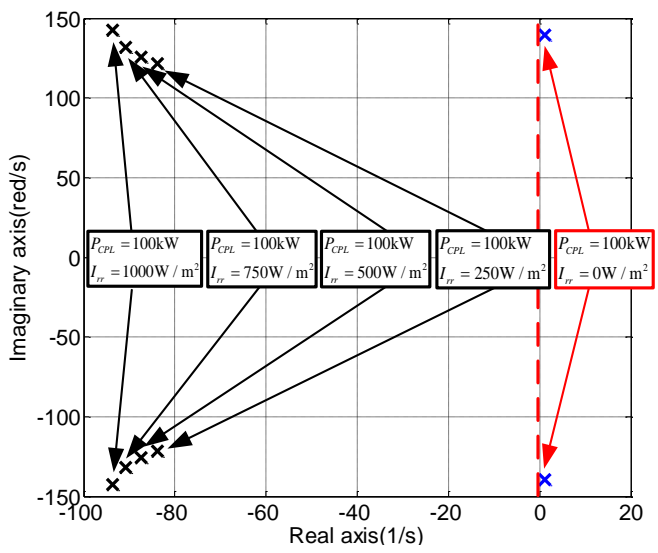

(a) Eigenvalues with the effect of irradiance changing.

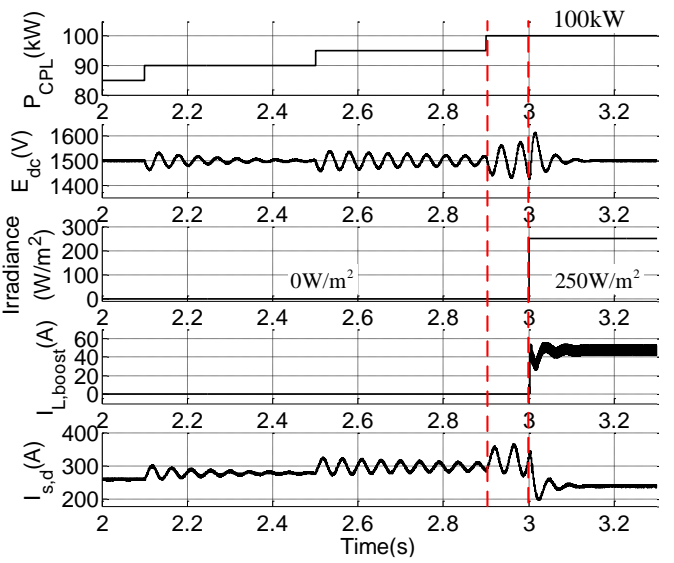

(b) Simulation result for changing irradiance.

Fig. 5. Effect of irradiance changing.

For irradiance greater than $0 \mathrm{~W} / \mathrm{m}^{2}$, the instability of the DCMGs because of the CPL does not occur. Therefore, this paper will consider only the case of the irradiance equal to $0 \mathrm{~W} / \mathrm{m}^{2}$ as the worst-case scenario because the system can become unstable before reaching the rated power. Moreover, the irradiance cannot be controlled if the system becomes unstable naturally. For example, the irradiance value was almost equal to $0 \mathrm{~W} / \mathrm{m}^{2}$ when the DCMGs are operated at night or on cloudy days. To predict the system stability in the worst-case scenario, the dominant poles for the CPL was increased from $80 \mathrm{~kW}$ to $100 \mathrm{~kW}$, and the DC bus voltage was regulated at $1500 \mathrm{~V}$ (see Fig. 6(a)). The simulation result of the worst-case scenario is shown in Fig. 6(b). 
Fig. 6 shows that the system will be unstable before reaching the rated power. This situation may damage the power electronic devices because of the huge oscillation at the DC bus. Focusing on this scenario helps mitigate the unstable operations until the rated power is achieved. Therefore, the stabilization technique to maintain the system always remains stable; this technique will be presented in the Section IV for the worst-case scenario.

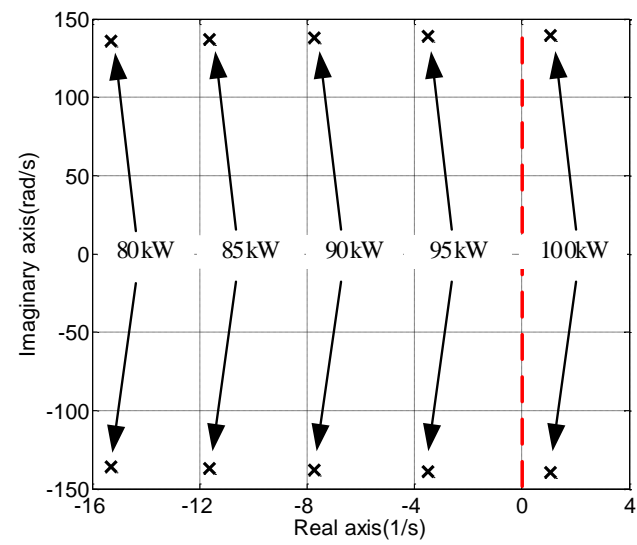

(a) Eigenvalues for the worst-case scenario.

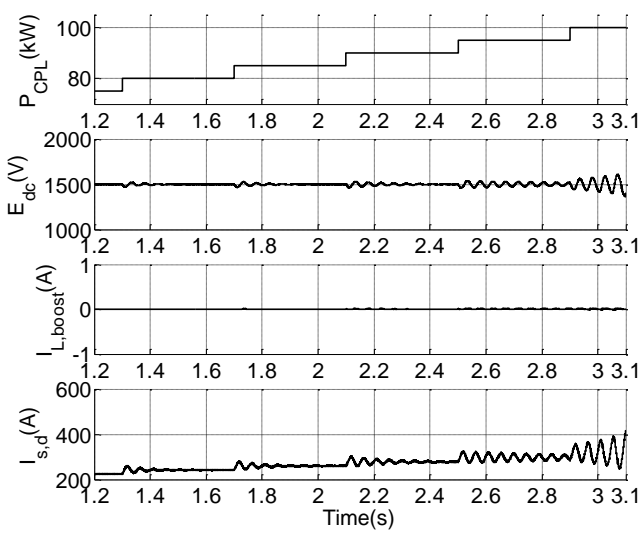

(b) Simulation result of the worst-case scenario.

Fig. 6. Stability analysis for the worst-case scenario.

\section{Stabilization of the DCMGs FEEDING AN IDEAL CPL}

The stability analysis from the previous section shows that the unstable operations do not occur within the rated power if $I_{r r}>0 \mathrm{~W} / \mathrm{m}^{2}$. Therefore, the DCMGs stabilization by using the loop-cancellation technique is only described for the worst-case scenario $\left(I_{r r}=0 \mathrm{~W} / \mathrm{m}^{2}\right)$. This technique is called loop-cancellation $[27,28]$ because the compensated signal can directly reduce the effect of $P_{C P L}$. The advantage of this technique is that it does not require additional components. The loop-cancellation technique involves the modification of the PI controllers of VSC [39] to mitigate the CPL effect. The DCMGs with the loop-cancellation technique can feed the CPL until the rated power is achieved, as shown in Fig. 1. However, the system components are similar to the system used in Section III, except for the controller of VSC. The PI controllers were used with loop-cancellation for system stabilization. The details of loop cancellation in Fig. 1 can be found in the grey area of Fig. 7.

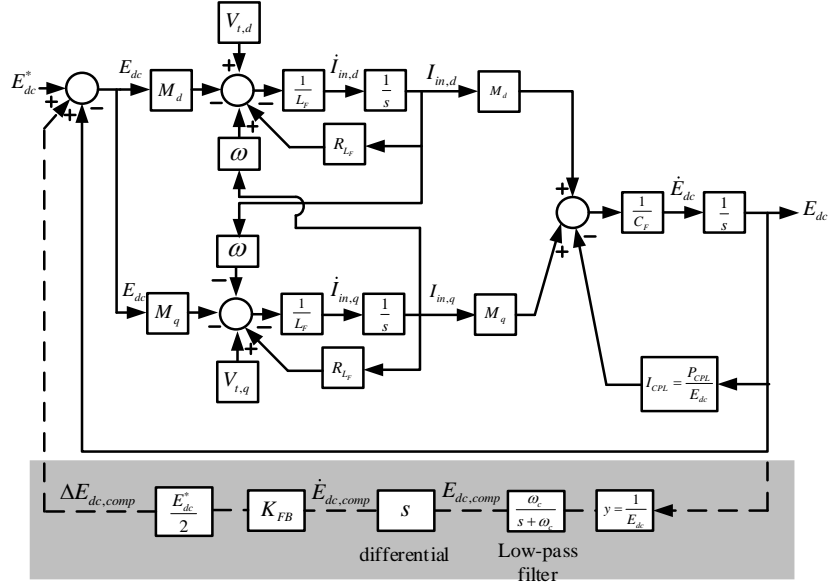

Fig. 7. Loop-cancellation technique for the DCMGs.

The block diagram in Fig. 7 is the control loop diagram of the VSC with the proposed mitigation approach. The CPL behaves as a negative impedance [22] in which $I_{C P L}=P_{C P L} / E_{d c}$. The CPL effect needs to be eliminated by detecting the output voltage at the DC bus $\left(E_{d c}\right)$. The $E_{d c}$ is then reversed with a low-pass filter to reduce the noise caused by the high-frequency switching device. The signal from the low-pass filter denoted by $E_{d c, c o m p}$ can be calculated by (4).

$$
E_{d c, \text { comp }}=\frac{\omega_{c}}{s+\omega_{c}} \cdot \frac{1}{E_{d c}}
$$

where $\omega_{c}$ is the cut-off frequency $(\mathrm{rad} / \mathrm{s})$, and $E_{d c}$ is the DC bus voltage $(\mathrm{V})$.

The $\omega_{c}$ is designed to be equal to the resonance frequency [28] in which $\omega_{c}$ is equal to $150 \mathrm{rad} / \mathrm{s}$ in this paper. From (4), the $E_{d c, \text { comp }}$ is opposite from $E_{d c}$. To consider only the oscillation during the transient, $E_{d c, c o m p}$ is then passed through the derivative resulting in the slope of the compensation value ( $\dot{E}_{d c, \text { comp }}$ ) as calculated in (5). After the derivative block, in steady state condition, the $\dot{E}_{d c, c o m p}$ will be equal to 0 because of the derivative of constant. Therefore, the loop-cancellation technique will affect to only the transient response. The oscillation of $\dot{E}_{d c, \text { comp }}$ is opposite to the oscillation of $E_{d c, \text { comp }}$. This oscillation is scaled by multiplied by $K_{F B}$ and $E_{d c}^{*} / 2$ as calculated in (6) in which the $\Delta E_{d c, \text { comp. }}$ is the compensation voltage value to create sufficient magnitude of compensating signal. The compensating signal $\Delta E_{d c, \text { comp. }}$ having the opposite oscillation of $E_{d c}$ will be injected into the summation block with positive sign. As s result, the oscillation of $E_{d c}$ during the unstable operation can be eliminated by $\Delta E_{d c, \text { comp. }}$.

$$
\begin{aligned}
& \dot{E}_{d c, \text { comp }}=\frac{d}{d t}\left(E_{d c, \text { comp }}\right) \\
& \Delta E_{d c, \text { comp }}=\dot{E}_{d c, \text { comp }} \frac{E_{d c}^{*}}{2} K_{F B}
\end{aligned}
$$


However, the magnitude of compensated signal $\Delta E_{d c, \text { comp }}$ must be designed to achieve the appropriate value of compensating signal. The magnitude of $\Delta E_{d c \text {,comp }}$ depends on the gain of $K_{F B}$. This gain will be adjusted until the effect of $P_{C P L}$ can be eliminated. It can be seen from Fig. 7 that after the loop cancellation is applied, the control loop of VSC is modified, as shown in the gray section of Fig. 7, by coding only in the microcontroller board. However, from Fig. 7 and (6), it is possible to calculate $M_{d}^{*}$ and $M_{q}^{*}$ with loop-cancellation as follows:

$$
\begin{aligned}
& M_{d}^{*}=\frac{1}{A_{r}}\left(\begin{array}{l}
E_{d c}^{*} K_{p v} K_{p i}-E_{d c} K_{p v} K_{p i}-E_{d c, c o m p} E_{d c}^{*} \frac{\omega_{c}}{2} K_{F B} K_{p v} K_{p i} \\
+\frac{E_{d c}^{*}}{E_{d c}} \frac{\omega_{c}}{2} K_{F B} K_{p v} K_{p i}+X_{v} K_{i v} K_{p i}-I_{i n, d} K_{p i}+X_{i d} K_{i i}
\end{array}\right) \\
& M_{q}^{*}=\frac{1}{A_{r}}\left(-I_{i n, q} K_{p i}+X_{i q} K_{i i}\right)
\end{aligned}
$$

Using the mathematical model of the DCMGs derived by using the DQ and GSSA methods (described in [40]), the $M_{d}$ and $M_{q}$ of (A-1) [40] can be replaced by the $M_{d}^{*}$ and $M_{q}^{*}$ values from (7). The dynamic model of DCMGs with the loop-cancellation technique can be expressed as in (A-2). To validate the model of (A-2), the intensive time-domain simulations of MATLAB by using the same parameters of Section II with $K_{F B}=2$ were used. The CPL was changed from $110 \mathrm{~kW}$ to $120 \mathrm{~kW}$ at $t=0.3 \mathrm{~s}$. The result is given in Fig. 8 . It can be seen that the proposed model of (A-2) can provide the correct responses for both transient and steady-state. Therefore, the derived model of (A-2) can be used to assess the $K_{F B}$ for eliminating the CPL effect.

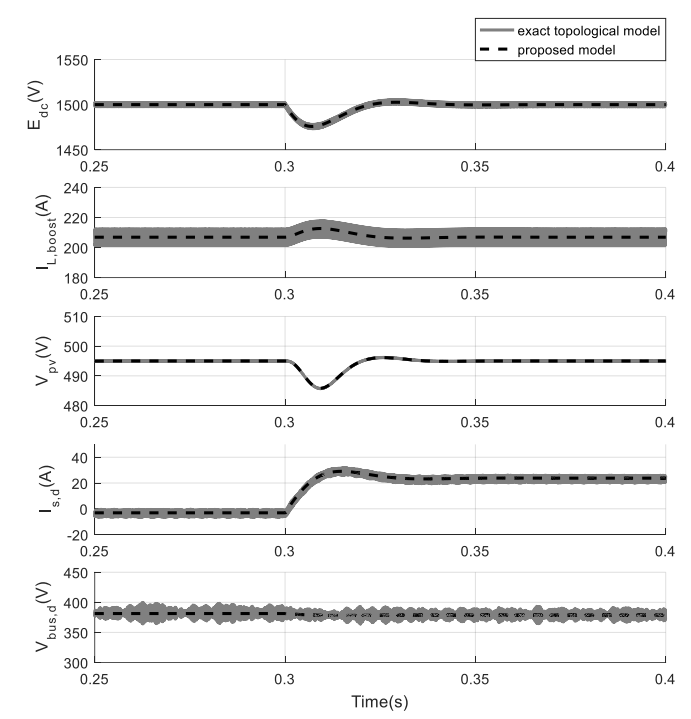

Fig. 8 Mathematical model validation of the considered system.

From (A-2), it is clear that the model is nonlinear. Performing the Taylor's series expansion and addressing only $1^{\text {st }}$-order terms, the linearized model of the DCMGs including the loop-cancellation technique can be derived. As mentioned above, the stabilization technique in this study will address only the worst-case for the DCMGs $\left(I_{r r}=0 \mathrm{~W} / \mathrm{m}^{2}\right)$ because, for all $I_{r r}>0 \mathrm{~W} / \mathrm{m}^{2}$, the unstable operation does not occur for all the power values below the rated ones for the DCMGs

For mitigation purpose, the $K_{F B}$ is adjusted until it is enough for eliminating the CPL effect. The appropriate $K_{F B}$ can be determined by the eigenvalue theorem with the linearized model of (A-2). The scenario is set as follows: the DC bus voltage was controlled at $1500 \mathrm{~V}$, and the irradiance was set to $0 \mathrm{~W} / \mathrm{m}^{2}$ for the worst-case scenario. An appropriate $K_{F B}$ needed to be found. Fig. 9(a) shows the dominant poles located at the right-hand side of the s-plane when the CPL is equal to $100 \mathrm{~kW}$. These poles indicate that the DCMGs is unstable operation for the worst-case scenario. However, if $K_{F B}=1$ (i.e., the proposed mitigation is applied), the system will become stable, and the dominant poles move back to the left-hand side of the s-plane. To confirm this analytical result, time-domain simulations in MATLAB/SimPowerSystem ${ }^{\circledR}$ environment were performed; the results are reported in Fig. 9(b).



(a) Worst-case scenario of the dominant poles of DCMGs including the mitigation technique.
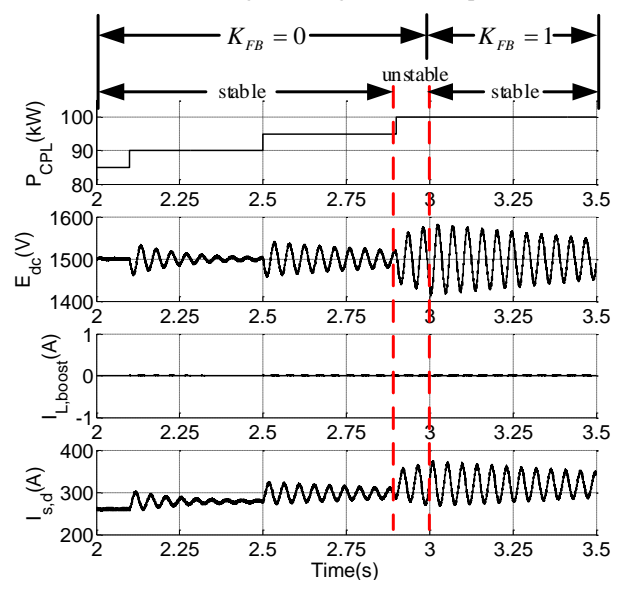

(b) Worst-case scenario simulation results of DCMGs including the mitigation technique.

Fig. 9. Worst-case scenario of DCMGs including the mitigation technique.

In Fig. 9(b), we can clearly see that the DCMGs with $K_{F B}=0$ is unstable at $t=3 \mathrm{~s}$ whereas $P_{C P L}=100 \mathrm{~kW}$. However, at $t>3 \mathrm{~s}$, the DCMGs can have stable operations by setting $K_{F B}=1$. Hence, the appropriated value of $K_{F B}$ should be investigated to ensure that the system will always be stable. 


\section{A. Design of the appropriated $K_{F B}$ value}

The system controller can be designed based on the desired natural frequency. The effect of the natural frequency [8] on the stability margin should be investigated because the system might go into unstable operations. In this paper, the bandwidth of the voltage loop natural frequency is considered within the range $150 \mathrm{rad} / \mathrm{s} \leq \omega_{n v} \leq 250 \mathrm{rad} / \mathrm{s}$. The instability line calculated from the proposed mathematical model without the instability mitigation ( $K_{F B}=0$ ) is shown in Fig. 10(a) for this natural frequency range.

From Fig. 10(a), we can see that the system becomes unstable within the rated power range $(<100 \mathrm{~kW})$, that is, when the CPL is greater than 98,87 , and $79 \mathrm{~kW}$ for the PI controller bandwidth equal to 150,200 , and $250 \mathrm{rad} / \mathrm{s}$, respectively. Fig. 10(b) shows the simulation results that confirm the analytical result of Fig. 10(a). Analysis of the stability conditions depending on the voltage control natural frequency leads to the conclusion that a mitigation technique is required if the system cannot maintain stability in the specified power range. The design of the appropriate $K_{F B}$ is illustrated in Fig. 11(a). The instability line in Fig.11(a) when $K_{F B}=3$ is located above the rated power for all the considered bandwidths. Hence, $K_{F B}=3$ can be used to mitigate the system for this case. Fig. 11(b) shows the simulation result of the DCMGs using $K_{F B}=3$; stable operations are maintained for all the possible voltage control natural frequencies and load powers within the rated range.

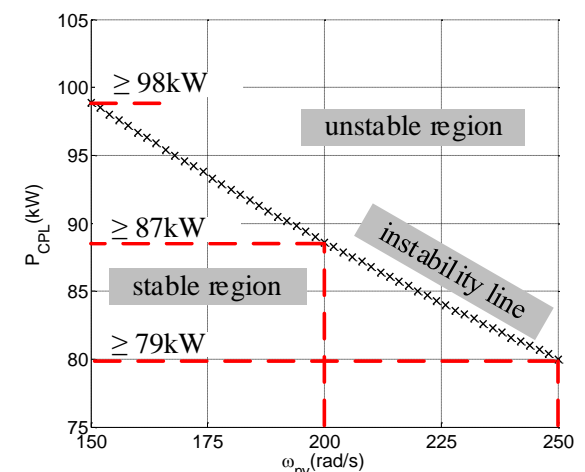

(a) In stability line for different values of the voltage control natural frequency.
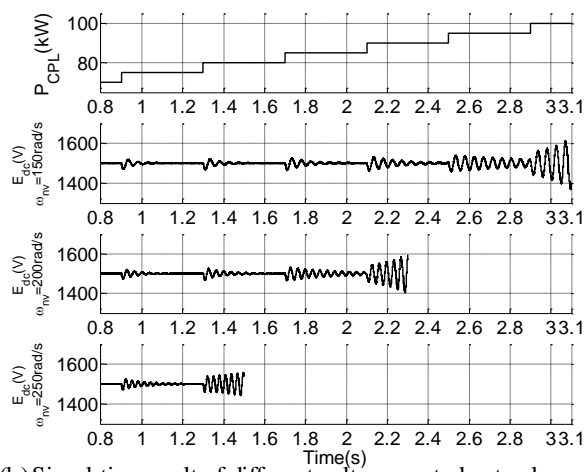

(b) Simulation result of different voltage control natural frequencies.

Fig. 10. Stability analysis for different values of the voltage control natural frequency.

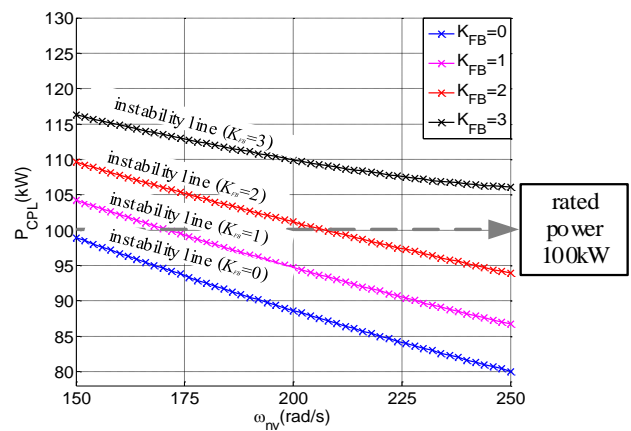

(a) Asses sment of the value.



(b) Simulation result of the DCMGs at $K_{F B}=3$

Fig. 11. Appropriated $K_{F B}$ value design.

\section{B. Evaluation of the appropriated $K_{F B}$ value using the hardware in the loop}

The hardware-in-loop (HIL) simulation was used to ensure that the DCMGs including the proposed loop-cancellation technique can be implemented in the microcontroller board programming. In this paper, the TMDSCOCK28335 board was used for the HIL simulation. The connection between the microcontroller board and MATLAB is shown in Fig. 12(a). The condition of the HIL simulation is operated as the exact topological simulation shown in Fig. 11(b). The HIL simulation results are depicted in Fig. 12(b); the sampling time of this simulation was set to $30 \mu \mathrm{s}$.

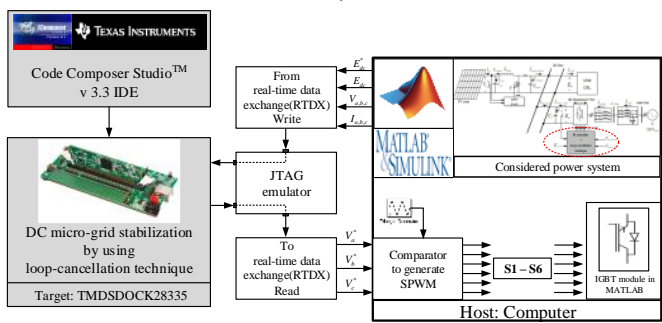

(a) Connection of the HIL simulation.

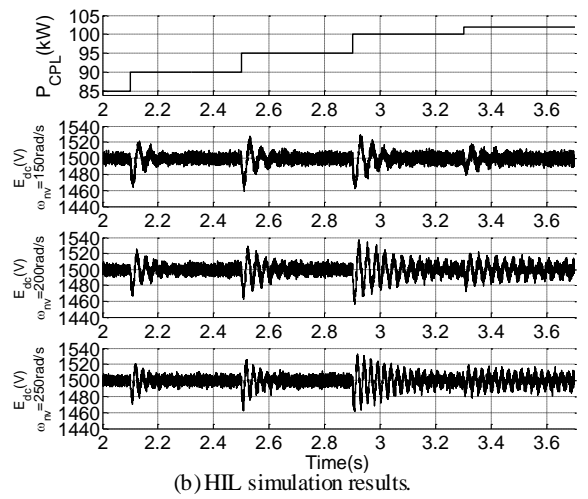

Fig. 12. Appropriated $K_{F B}$ investigation using the HIL simulation. 
Fig. 11(b) and Fig. 12(b) show the results of the exact topological and HIL simulations; the DC bus voltage response is stable when the CPL is set at the rated power of DCMGs if the loop-cancellation technique with $K_{F B}=3$ is applied. To consider the response for stable operations, the exact topological and HIL simulation results when the CPL is increased from $70 \mathrm{~kW}$ to $75 \mathrm{~kW}$ at $t=0.9 \mathrm{~s}$ with $K_{F B}=3$ are addressed in Fig. 13.

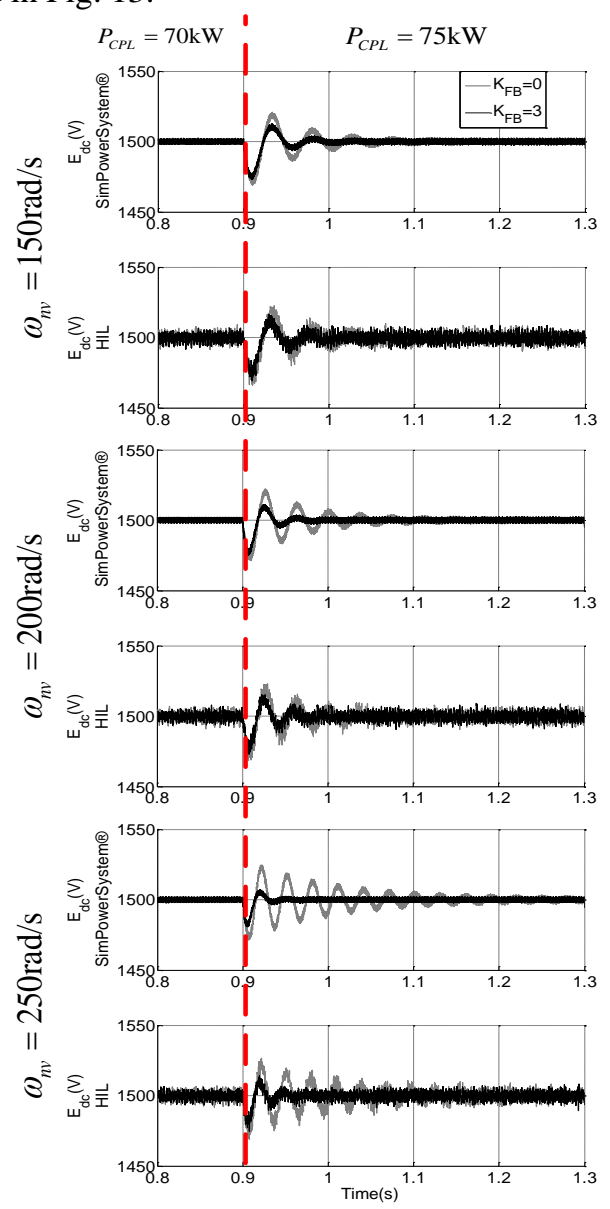

Fig. 13. Simulation result of the normal DCMGs operation.

From Fig. 13, the DC bus voltage is well regulated to $1500 \mathrm{~V}$. Hence, the loop-cancellation technique with $K_{F B}=3$ can be applied in normal operations. Fortunately, the transient response under the loop-cancellation technique can be improved as confirmed by the results shown in Fig. 13.

Therefore, the proposed mitigation technique can always be activated in the system to ensure that it is stable under the normal operation scenario. However, the method to determine the $K_{F B}$ value needs to be reconsidered if the system parameters are changed because these parameters can significantly stabilize the system. The experimental validation from the testing rig is presented in Section V.

\section{EXPERIMENT RESULTS}

In the previous section, the mitigation technique based on the loop-cancellation method has been proposed to avoid unstable operations of the DCMGs. The proposed solution can be applied in all modes; however, this solution is essential in the worst-case scenario where the system operates at no irradiance $\left(0 \mathrm{~W} / \mathrm{m}^{2}\right)$. The analytical studies in Section IV have shown that system stabilization can be achieved. In this section, experimental proof is provided for the proposed solution. The testing rig of the system used in the study is shown in the parts of $\mathrm{B}$ and $\mathrm{C}$ from Fig. 1. It consists of the bidirectional VSC located between the DC bus and three-phase power system, and the CPL is represented with the controlled buck-boost converter. For the buck-boost converter, the adaptive Tabu search [37] was used to design the PI controller for achieving the optimal output response, which was as close as possible to the ideal CPL. The details of the testing rig are provided in Fig. 14.

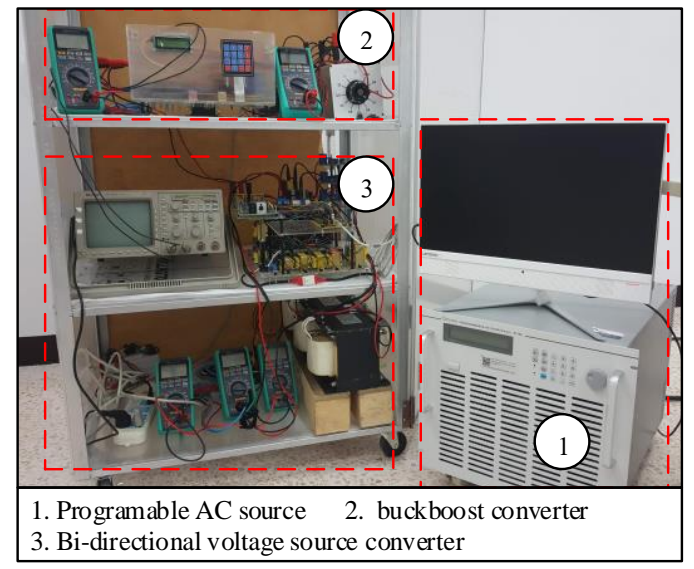

Fig. 14. Details of the testing rig.

The rated power of the test-bench system was scaled down to $100 \mathrm{~W}$ for the experiments. The DC bus voltage was controlled to $100 \mathrm{~V}$, and the resistive load of the buck-boost converter was $40 \Omega$. The output voltage of the buck-boost converter was tightly regulated by the PI controller; therefore, the output power of this converter can be calculated as $P_{\text {out }}=V_{o, \text { buckboost }}^{2} / R_{\text {Load }}$ [41] in which the $P_{\text {out }}$ will be equal to $P_{C P L}$. The stability analysis has been conducted for varied control bandwidth, and theoretically expected stability borderline is shown in Fig. 15(a) with the symbol ' $x$ '. It can be seen that the trend of unstable points from testing rig as shown in the red circles in Fig. 15(a) are similar to the instability line predicted theoretically. The experimental results for controller bandwidths 150, 200 and $250 \mathrm{rad} / \mathrm{s}$ are shown in Fig. 15(b), Fig. 15(c) and Fig. 15(d), respectively.

In experimental results (Figs. 15(b) to $15(\mathrm{~d})$ ), the $\mathrm{CH} 1$ line is the response of the DC bus voltage. The output voltage and current of the buck-boost converter are represented in $\mathrm{CH} 2$ and $\mathrm{CH} 3$, respectively. In Fig. 15(b), the system with the controller bandwidth equal to $150 \mathrm{rad} / \mathrm{s}$ becomes unstable at $V_{\text {o,buckcoost }}=57 \mathrm{~V} ; P_{\text {out }}$ was calculated to be $81.23 \mathrm{~W}$. In addition, the testing results shown in Fig. 15(c) and Fig. 15(d) for the controller bandwidths $200 \mathrm{rad} / \mathrm{s}$ and $250 \mathrm{rad} / \mathrm{s}$ show that unstable operations occur at $V_{\text {o,buckcoost }}=54 \mathrm{~V}(72.9 \mathrm{~W})$ and $V_{\text {o,buckoost }}=51 \mathrm{~V} \quad(65.03 \mathrm{~W})$. Clearly, the higher bandwidth is less stable. The system becomes unstable before the rated power $(100 \mathrm{~W})$ is achieved for all bandwidths; therefore, mitigation is certainly required. Applying the proposed loop-cancellation technique (as discussed in 
Section IV) is required. The instability lines are then calculated (as proposed above) by varying $K_{F B}$, as shown in Fig. 16(a). The results show that when $K_{F B}$ is set equal to 3, the system is always stable for $\omega_{n v}=150-250 \mathrm{rad} / \mathrm{s}$. The experimental results of the mitigated system with $K_{F B}=3$ for the controller bandwidths equal to 150,200 , and $250 \mathrm{rad} / \mathrm{s}$ are depicted in Fig. 16(b) to Fig. 16(d), respectively. From Figs.16(b) to 16(d), the experimental testing with

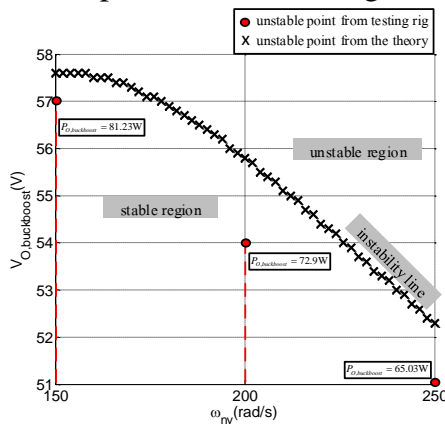

(a) The unstable point from the testing rig compared with the instability.

$\omega_{n v}=200 \mathrm{rad} / \mathrm{s}$



(c) Results obtained from the testing rig at $\omega_{n v}=200 \mathrm{rad} / \mathrm{s}$.

Fig. 15. Results from the testing rig compared with the instability.

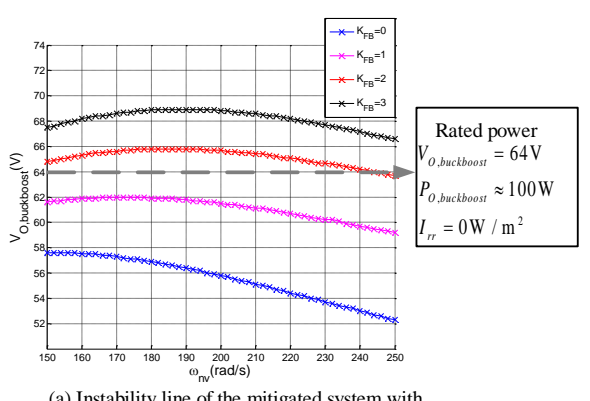

(a) Instability line of the mitigated system with various Values.

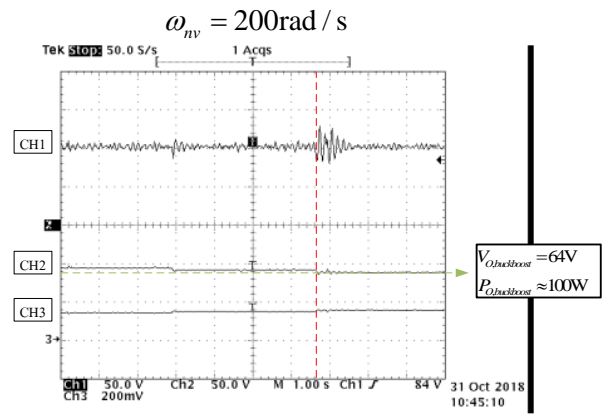

(c) DCMGs stabilization with $K_{F B}=3$ at $\omega_{m}=200 \mathrm{rad} / \mathrm{s}$. loop cancellation ( $K_{F B}=3$ ) can operate until the rated power $(100 \mathrm{~W})$. These results confirm that the stability margins of DCMG systems can be significantly expanded by applying the proposed loop-cancellation technique. As a result, from the HIL simulation and experiment, the DCMGs is always stable within the rated power range. Modifying only the control loop (i.e., the control code) of the bi-directional VSC can make the system more stable without introducing any hardware changes to the system.



(b) Results obtained from the testing rig at $\omega_{m}=150 \mathrm{rad} / \mathrm{s}$.

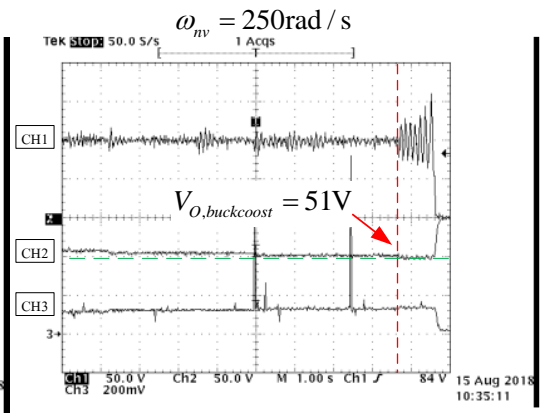

(d) Results obtained from the testing rig at $\omega_{n v}=250 \mathrm{rad} / \mathrm{s}$.



(b) DCMGs stabilization with $K_{F B}=3$ at $\omega_{n v}=150 \mathrm{rad} / \mathrm{s}$.

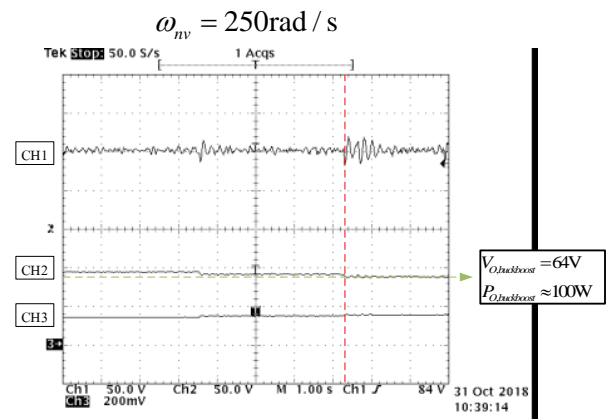

(d) DCMGs stabilization with $K_{F B}=3$ at $\omega_{r v}=250 \mathrm{rad} / \mathrm{s}$.

Fig. 16 Results of DCMGs stabilization 


\section{CONCLUSION}

This paper presents the stabilization of DCMGs feeding the CPL by using the loop-cancellation technique. It was shown that the unstable point depends on the CPL level. In addition, the irradiance of PV arrays also affects the stability margin. The stability study shows that the system will be unstable before the rated power when the irradiance is equal to $0 \mathrm{~W} / \mathrm{m}^{2}$. Therefore, the instability mitigation approach using the loopcancellation technique was applied to keep the system stable until the rated power was achieved. The loop-cancellation technique can directly eliminate the CPL effect. Moreover, this technique does not require other passive components. The results show that by using this technique, the proposed DCMGs could supply the CPL as long as the rated power for all the cases of the controller bandwidth varied. When the proposed mitigation technique was used, the system performance could be improved for both the transient and steady-state responses. Good agreement was reached among the theoretical results, HIL simulation, and the experimental results

\section{REFERENCES}

[1] N. K. M. A. Alrikabi, "Renewable Energy Types," Journal of Clean Energy Technologies, vol. Vol.2, no. 1, pp. 61-64, 2014.

[2] A. Kwasinski, "Quantitative Evaluation of DC Microgrids Availability: Effects of System Architecture and Converter Topology Design Choices," IEEE Transactions on Power Electronics, vol. 26, no. 3, pp. 835-851, 2011.

[3] A. Emadi , M. Ehsani , and J. M. Miller, "Electric and Hybrid Electric Vehicles," in Vehicular Electric Power Systems(Power Engineering (Willis): CRC Press, 2003.

[4] D. Boroyevich, I. Cvetkovic, D. Dong, R. Burgos, F. Wang, and F. Lee, "Future electronic power distribution systems a contemplative view," in 2010 12th International Conference on Optimization of Electrical and Electronic Equipment, 2010, pp. 1369-1380.

[5] T. Dragicevic, S. Sucic, J. C. Vasquez, and J. M. Guerrero, "Flywheel-Based Distributed Bus Signalling Strategy for the Public Fast Charging Station," IEEE Transactions on Smart Grid, vol. 5, no. 6, pp. 2825-2835, 2014.

[6] Z. Jiang and R. A. Dougal, "A Compact Digitally Controlled Fuel Cell/Battery Hybrid Power Source," IEEE Transactions on Industrial Electronics, vol. 53, no. 4, pp. 1094-1104, 2006.

[7] M. Kumar, S. C. Srivastava, S. N. Singh, and M. Ramamoorty, "Development of a control strategy for interconnection of islanded direct current microgrids," IET Renewable Power Generation, vol. 9, no. 3, pp. 284-296, 2015.

[8] K. Areerak, T. Wu, S. V. Bozhko, G. M. Asher, and D. W. P. Thomas, "Aircraft Power System Stability Study Including Effect of Voltage Control and Actuators Dynamic," IEEE Transactions on Aerospace and Electronic Systems, vol. 47, no. 4, pp. 2574-2589, 2011.

[9] C. H. Rivetta, A. Emadi, G. A. Williamson, R. Jayabalan, and B. Fahimi, "Analysis and control of a buck DC-DC converter operating with constant power load in sea and undersea vehicles," IEEE Transactions on Industry Applications, vol. 42, no. 2, pp. 559-572, 2006.

[10] A. B. Jusoh, "The instability effect of constant power loads," in PECon 2004. Proceedings. National Power and Energy Conference, 2004., 2004, pp. 175-179.

[11] A. Emadi, A. Khaligh, C. H. Rivetta, and G. A. Williamson, "Constant power loads and negative impedance instability in automotive systems: definition, modeling, stability, and control of power electronic converters and motor drives," IEEE Transactions on Vehicular Technology, vol. 55, no. 4, pp. 11121125, 2006.

[12] S. Kim and S. S. Williamson, "Negative impedance instability compensation in more electric aircraft DC power systems using state space pole placement control," in 2011 IEEE Vehicle Power and Propulsion Conference, 2011, pp. 1-6.

[13] J. Mahdavi, A. Emaadi, M. D. Bellar, and M. Ehsani, "Analysis of power electronic converters using the generalized state-space averaging approach," IEEE Transactions on Circuits and Systems I: Fundamental Theory and Applications, vol. 44, no. 8, pp. 767-770, 1997.

[14] A. Emadi, "Modelling and analysis of multi-converter DC power electronic systems using the generalized state space averaging method," in Industrial Electronics Society, 2001. IECON '01. The 27th Annual Conference of the IEEE, 2001, vol. 2, pp. 1001-1007 vol.2.

[15] A. Emadi, "Modeling of power electronic loads in AC distribution systems using the generalized State-space averaging method," IEEE Transactions on Industrial Electronics, vol. 51, no. 5, pp. 992-1000, 2004.

[16] L. Han, J. Wang, and D. Howe, "State-space average modelling of 6- and 12-pulse diode rectifiers," in 2007 European Conference on Power Electronics and Applications, 2007, pp. 110.

[17] C. T. Rim, D. Y. Hu, and G. H. Cho, "Transformers as equivalent circuits for switches: general proofs and D-Q transformation-based analyses," IEEE Transactions on Industry Applications, vol. 26, no. 4, pp. 777-785, 1990.

[18] C. T. Rim, N. S. Choi, G. C. Cho, and G. H. Cho, "A complete DC and AC analysis of three-phase controlled-current PWM rectifier using circuit D-Q transformation," IEEE Transactions on Power Electronics, vol. 9, no. 4, pp. 390-396, 1994.

[19] H. Soo-Bin, C. Nam-Sup, R. Chun-Taik, and C. Gyu-Hyeong, "Modeling and analysis of static and dynamic characteristics for buck-type three-phase PWM rectifier by circuit DQ transformation," IEEE Transactions on Power Electronics, vol. 13, no. 2, pp. 323-336, 1998.

[20] K. Areerak et al., "The stability analysis of AC-DC systems including actuator dynamics for aircraft power systems," in 2009 13th European Conference on Power Electronics and Applications, 2009, pp. 1-10.

[21] C. M. Wildrick, F. C. Lee, B. H. Cho, and B. Choi, "A method of defining the load impedance specification for a stable distributed power system," IEEE Transactions on Power Electronics, vol. 10, no. 3, pp. 280-285, 1995.

[22] E. Hossain, R. Perez, A. Nasiri, and S. Padmanaban, "A Comprehensive Review on Constant Power Loads Compensation Techniques," IEEE Access, vol. 6, pp. 3328533305, 2018.

[23] M. Cespedes, L. Xing, and J. Sun, "Constant-Power Load System Stabilization by Passive Damping," IEEE Transactions on Power Electronics, vol. 26, no. 7, pp. 1832-1836, 2011.

[24] A. M. Rahimi and A. Emadi, "Active Damping in DC/DC Power Electronic Converters: A Novel Method to Overcome the Problems of Constant Power Loads," IEEE Transactions on Industrial Electronics, vol. 56, no. 5, pp. 1428-1439, 2009.

[25] A. A. A. Radwan and Y. A. R. I. Mohamed, "Linear Active Stabilization of Converter-Dominated DC Microgrids," IEEE Transactions on Smart Grid, vol. 3, no. 1, pp. 203-216, 2012.

[26] A. Khaligh, A. M. Rahimi, and A. Emadi, "Negative Impedance Stabilizing Pulse Adjustment Control Technique for DC/DC Converters Operating in Discontinuous Conduction Mode and Driving Constant Power Loads," IEEE Transactions on Vehicular Technology, vol. 56, no. 4, pp. 2005-2016, 2007.

[27] K. Areerak, T. Sopapirm, S. Bozhko, C. I. Hill, A. Suyapan, and K. Areerak, "Adaptive Stabilization of Uncontrolled Rectifier 
Based AC-DC Power Systems Feeding Constant Power Loads," IEEE Transactions on Power Electronics, vol. 33, no. 10, pp. 8927-8935, 2018.

[28] A. M. Rahimi, G. A. Williamson, and A. Emadi, "LoopCancellation Technique: A Novel Nonlinear Feedback to Overcome the Destabilizing Effect of Constant-Power Loads," IEEE Transactions on Vehicular Technology, vol. 59, no. 2, pp. 650-661, 2010

[29] X. Lu, K. Sun, J. M. Guerrero, J. C. Vasquez, L. Huang, and J. Wang, "Stability Enhancement Based on Virtual Impedance for DC Microgrids With Constant Power Loads," IEEE Transactions on Smart Grid, vol. 6, no. 6, pp. 2770-2783, 2015.

[30] A. A. A. Radwan and Y. A. I. Mohamed, "Linear Active Stabilization of Converter-Dominated DC Microgrids," IEEE Transactions on Smart Grid, vol. 3, no. 1, pp. 203-216, 2012.

[31] S. S. Alli, S. Jovanović, P. Poure, and E. Jamshidpour, "MPPT and output voltage control of Photovoltaic systems using a Single-Switch DC-DC converter," in 2016 IEEE International Energy Conference (ENERGYCON), 2016, pp. 1-6.

[32] C. Rivetta, G. A. Williamson, and A. Emadi, "Constant power loads and negative impedance instability in sea and undersea vehicles: statement of the problem and comprehensive largesignal solution," in IEEE Electric Ship Technologies Symposium, 2005., 2005, pp. 313-320.

[33] V. Grigore, J. Hatonen, J. Kyyra, and T. Suntio, "Dynamics of a buck converter with a constant power load," in PESC 98 Record. 29th Annual IEEE Power Electronics Specialists Conference (Cat. No.98CH36196), 1998, vol. 1, pp. 72-78 vol.1.

[34] J. Pakdeeto, K.-N. Areerak, and K.-L. Areerak, "The Stability Analysis of DC Micro-Grid Systemwith PV Array," The 2018
International Electrical Engineering Congress (iEECON2018), Krabi, Thailand, pp. 128-131, March 7-9 2018.

[35] J. Pakdeeto, K.-N. Areerak, and K.-L. Areerak, "Modelling and Stability Analysis of AC-DC Power Systems Feeding a Speed Controlled DC Motor," Journal of Electrical Engineering \& Technology, vol. 13, no. 4, pp. 1566-1577, 2018.

[36] K. Areerak, S. V. Bozhko, G. M. Asher, L. D. Lillo, and D. W. P. Thomas, "Stability Study for a Hybrid AC-DC More-Electric Aircraft Power System," IEEE Transactions on Aerospace and Electronic Systems, vol. 48, no. 1, pp. 329-347, 2012.

[37] J. Pakdeeto, R. Chanpittayagit, K. Areerak, and K. Areerak, "The Optimal Controller Design of Buck-Boost Converter by using Adaptive Tabu Search Algorithm Based on State-Space Averaging Model," (in En), Journal of Electrical Engineering \& Technology, vol. Volume 12, no. 3, pp. pp. 1146-1155, 05/01 2017.

[38] H. Ossenbrink, H. Müllejans, R. Kenny, and E. Dunlop, "1.39 Standards in Photovoltaic Technology," in Comprehensive Renewable Energy, A. Sayigh, Ed. Oxford: Elsevier, 2012, pp. 787-803.

[39] T. F. Wu, C. H. Chang, L. C. Lin, G. R. Yu, and Y. R. Chang, "DC-Bus Voltage Control With a Three-Phase Bidirectional Inverter for DC Distribution Systems," IEEE Transactions on Power Electronics, vol. 28, no. 4, pp. 1890-1899, 2013.

[40] J. Pakdeeto, K.-N. Areerak, and K.-L. Areerak, "Large-Signal Model of DC Micro-grid Systems Feeding a Constant Power Load," The 2017 International Electrical Engineering Congress (iEECON2017), Pattaya, Thailand, pp. 21-24, March 8-10 2017.

[41] M. H. Rashid, Power electronics : devices, circuits, and applications. 2014.

\section{Appendix}

The mathematical model without loop cancellation technique derived from the combination between DQ and GSSA methods is shown in (A-1). However, the model considering the loop cancellation technique to mitigation the unstable operation can be given in (A-2).

$$
\begin{aligned}
& \dot{I}_{s, d}=-\frac{R_{e q}}{L_{e q}} I_{s, d}+\omega I_{s, q}-\frac{1}{L_{e q}} V_{b u s, d}+\frac{1}{L_{e q}} V_{s, d} \\
& \dot{I}_{s, q}=-\omega I_{s, d}-\frac{R_{e q}}{L_{e q}} I_{s, q}-\frac{1}{L_{e q}} V_{b u s, q}+\frac{1}{L_{e q}} V_{s, q} \\
& \dot{V}_{\text {bus }, d}=\frac{1}{C_{e q}} I_{s, d}+\omega V_{b u s, q}-\frac{1}{C_{e q}} I_{i n, d} \\
& \dot{V}_{b u s, q}=\frac{1}{C_{e q}} I_{s, q}-\omega V_{b u s, d}-\frac{1}{C_{e q}} I_{i n, q} \\
& \dot{I}_{i n, d}=\frac{1}{L_{F}} V_{b u s, d}-\frac{R_{L_{F}}}{L_{F}} I_{i n, d}+\omega I_{i n, q}-\frac{K_{p v} K_{p i} E_{d c}^{*} E_{d c}}{A_{r} L_{F}}+\frac{K_{p v} K_{p i} E_{d c} E_{d c}}{A_{r} L_{F}}-\frac{K_{i v} K_{p i} E_{d c} X_{v}}{A_{r} L_{F}}+\frac{K_{p i} I_{i n, d} E_{d c}}{A_{r} L_{F}}-\frac{K_{i i} E_{d c} X_{i d}}{A_{r} L_{F}} \\
& \dot{I}_{i n, q}=\frac{1}{L_{F}} V_{b u s, q}-\omega I_{i n, d}-\frac{R_{L_{F}}}{L_{F}} I_{i n, q}+\frac{K_{p i} I_{i n, q} E_{d c}}{A_{r} L_{F}}-\frac{K_{i i} E_{d c} X_{i q}}{A_{r} L_{F}} \\
& \dot{E}_{d c}=\frac{K_{p v} K_{p i} E_{d c}^{*} I_{i n, d}}{A_{r} C_{F}}-\frac{K_{p v} K_{p i} E_{d c} I_{i n, d}}{A_{r} C_{F}}+\frac{K_{i v} K_{p i} I_{i n, d} X_{v}}{A_{r} C_{F}}-\frac{K_{p i} I_{i n, d} I_{i n, d}}{A_{r} C_{F}}+\frac{K_{i i} I_{i n, d} X_{i d}}{A_{r} C_{F}}-\frac{K_{p i} I_{i n, q} I_{i n, q}}{A_{r} C_{F}}+\frac{K_{i i} I_{i n, q} X_{i q}}{A_{r} C_{F}}+\left(1-d^{*}\right) \frac{I_{L, b o o s t}}{C_{F}}-\frac{P_{C P L}}{C_{F} E_{d c}} \\
& \dot{X}_{i d}=K_{p v} E_{d c}^{*}-K_{p v} E_{d c}+K_{i v} X_{v}-I_{i n, d} \\
& \dot{X}_{i q}=-I_{i n, q} \\
& \dot{X}_{v}=E_{d c}^{*}-E_{d c} \\
& \dot{I}_{L, \text { boost }}=\frac{V_{p v}}{L_{\text {boost }}}-\left(1-d^{*}\right) \frac{E_{d c}}{L_{\text {boost }}} \\
& \dot{V}_{p v}=-\frac{I_{L, b o s t}}{C_{p v}}+\frac{N_{p}}{C_{p v}}\left[\left[\left(I_{s . c .}+K_{i}\left(T-T_{r e f}\right)\right)\left(\frac{G}{G_{r e f}}\right)\right]-\left[\left(\frac{I_{s . c .}}{\left(\frac{\left.V_{\text {o.c. }}\right)}{n C V_{t}}\right)}-1\right)\left(\frac{T}{T_{r e f}}\right)^{3}\left(e^{\left(\frac{T}{T_{r e f}}-1\right)\left(\frac{E_{g}}{n C V_{t}}\right)}\right)\left(e^{\left(\frac{V_{p v}}{N_{s} n C V_{t}}+\frac{I_{p v} R_{s}}{N_{p} n C V}\right)}-1\right)\right]\right]
\end{aligned}
$$




$$
\begin{aligned}
& \dot{I}_{s, d}=-\frac{R_{e q}}{L_{e q}} I_{s, d}+\omega I_{s, q}-\frac{1}{L_{e q}} V_{b u s, d}+\frac{1}{L_{e q}} V_{s, d} \\
& \dot{I}_{s, q}=-\omega I_{s, d}-\frac{R_{e q}}{L_{e q}} I_{s, q}-\frac{1}{L_{e q}} V_{b u s, q}+\frac{1}{L_{e q}} V_{s, q} \\
& \dot{V}_{\text {bus }, d}=\frac{1}{C_{e q}} I_{s, d}+\omega V_{b u s, q}-\frac{1}{C_{e q}} I_{i n, d} \\
& \dot{V}_{\text {bus }, q}=\frac{1}{C_{e q}} I_{s, q}-\omega V_{b u s, d}-\frac{1}{C_{e q}} I_{i n, q} \\
& \dot{I}_{i n, d}=\frac{1}{L_{F}} V_{b u s, d}-\frac{R_{L_{F}}}{L_{F}} I_{i n, d}+\omega I_{i n, q}-\frac{K_{p v} K_{p i} E_{d c}^{*} E_{d c}}{L_{F}}+\frac{K_{p v} K_{p i} E_{d c} E_{d c}}{L_{F}}-\frac{\omega_{c} K_{F B} K_{p v} K_{p i} \frac{E_{d c}^{*}}{E_{d c}} E_{d c}}{2 L_{F}}+\frac{\omega_{c} K_{F B} K_{p v} K_{p i} E_{d c, c o m p} E_{d c}^{*} E_{d c}}{2 L_{F}} \\
& -\frac{K_{i v} K_{p i} E_{d c} X_{v}}{L_{F}}+\frac{K_{p i} I_{i n, d} E_{d c}}{L_{F}}-\frac{K_{i i} E_{d c} X_{i d}}{L_{F}} \\
& \dot{I}_{i n, q}=\frac{1}{L_{F}} V_{b u s, q}-\omega I_{i n, d}-\frac{R_{L_{F}}}{L_{F}} I_{i n, q}+\frac{K_{p i} I_{i n, q} E_{d c}}{L_{F}}-\frac{K_{i i} E_{d c} X_{i q}}{L_{F}} \\
& \left\{\dot{E}_{d c}=\frac{K_{p v} K_{p i} E_{d c}^{*} I_{i n, d}}{C_{F}}-\frac{K_{p v} K_{p i} E_{d c} I_{i n, d}}{C_{F}}+\frac{\omega_{c} K_{F B} K_{p v} K_{p i} \frac{E_{d c}^{*}}{E_{d c}} I_{i n, d}}{2 C_{F}}-\frac{\omega_{c} K_{F B} K_{p v} K_{p i} E_{d c, c o m p} E_{d c}^{*} I_{i n, d}}{2 C_{F}}+\frac{K_{i v} K_{p i} I_{i n, d} X_{v}}{C_{F}}-\frac{K_{p i} I_{i n, d} I_{i n, d}}{C_{F}}\right. \\
& +\frac{K_{i i} I_{i n, d} X_{i d}}{C_{F}}-\frac{K_{p i} I_{i n, q} I_{i n, q}}{C_{F}}+\frac{K_{i i} I_{i n, q} X_{i q}}{C_{F}}+\left(1-d^{*}\right) \frac{I_{L, b o o s t}}{C_{F}}-\frac{P_{C P L}}{C_{F} E_{d c}} \\
& \dot{X}_{i d}=K_{p v} E_{d c}^{*}-K_{p v} E_{d c}+\frac{\omega_{c}}{2} K_{F B} K_{p v} \frac{E_{d c}^{*}}{E_{d c}}-\frac{\omega_{c}}{2} E_{d c, c o m p} K_{F B} K_{p v} E_{d c}^{*}+K_{i v} X_{v}-I_{i n, d} \\
& \dot{X}_{i q}=-I_{i n, q} \\
& \dot{X}_{v}=E_{d c}^{*}-E_{d c}+\frac{\omega_{c}}{2} K_{F B} \frac{E_{d c}^{*}}{E_{d c}}-\frac{\omega_{c}}{2} E_{d c, \text { comp }} K_{F B} E_{d c}^{*} \\
& \dot{I}_{L, \text { boost }}=\frac{V_{p v}}{L_{\text {boost }}}-\left(1-d^{*}\right) \frac{E_{d c}}{L_{\text {boost }}} \\
& \dot{V}_{p v}=-\frac{I_{L, b o o s t}}{C_{p v}}+\frac{N_{p}}{C_{p v}}\left[\left[\left(I_{s . c .}+K_{i}\left(T-T_{r e f}\right)\right)\left(\frac{G}{G_{r e f}}\right)\right]-\left[\left(\frac{I_{s . c .}}{\left(\frac{V_{o c .}}{n C V_{t}}\right)}-1\right)\left(\frac{T}{T_{r e f}}\right)^{3}\left(e^{\left(\frac{T}{T_{r e f}}-1\right)\left(\frac{E_{s}}{n C V_{t}}\right)}\right)\left(e^{\left(\frac{V_{p v}}{N_{s} n C V_{t}}+\frac{I_{p} R_{s}}{N_{p} n C V}\right)}-1\right)\right]\right] \\
& \dot{E}_{d c, \text { comp }}=\frac{\omega_{c}}{E_{d c}}-\omega_{c} E_{d c, c o m p}
\end{aligned}
$$

